\title{
Effect of Gross Motor Activity on Self-Regulation of Preschool Children
}

\author{
Luthfatun Nisa ${ }^{1}$ and Wuri Wuryandani ${ }^{2}$ \\ ${ }^{1}$ Early Childhood Education Department, Master Program, Yogyakarta State University, Indonesia \\ ${ }^{2}$ Elementary Education Program, Yogyakarta State University
}

\begin{abstract}
The benefits of gross motor activity for children's development are maximized when children stimulated well and one of the benefits of gross motor activity is improved the children self-regulation. The development of early childhood self-regulation is often considered an early life marker for later life successes. This study aims to determine how the effect of gross motor activity on self-regulation of children, especially for 5-6 years old. The focus of the discussion in this study has revealed the self-regulation of preschool and impact of the gross motor activity on self-regulation of preschool children. The subject was two kindergarten in Yogyakarta Middle Java Indonesia and the participants consisted of 40 kindergarten children (25 girls and 15 boys). Thus, data were used for further analysis and using regression method was computed for determining how the effect of gross motor activity on self-regulation behavior of preschool children. The result of the study indicated that gross motor activity includes object control and locomotor activities are contributed on children's self-regulation. Both of skills that object control (dribble, underhand rolling, catching the ball, and etc) and locomotor (slide, gallop, hop, and etc). We found the significant impact of the gross motor activity on self-regulation of preschool children, especially for 5-6 years old, and the measure of self-regulation is Head-Toes-Knees-Shoulders task (HTKS). The other result showed that the number of children in the classroom has a different impact on the children self-regulation. The small groups are better than big groups in the self-regulation skill. The effect of the object control and locomotor activities on children's self-regulation are discussed. The recommendation was provided to parents, academics, practitioners in the discussion that especially emphasized addressing the need to increase opportunities for children's access to a gross motor activity and to improve teachers' professional competencies in good stimulation.
\end{abstract}

Keywords: Preschool, Self-Regulation, HTKS, Gross Motor Activity

\section{Introduction}

Early childhood self-regulation development is often considered an early life marker for later academic and life successes (Montory JJ, McClelland MM, Morrison FJ, Bowles RP, \& Skibbe LE, 2016). Self regulation for preschool children is believed to be important on children. Through self-regulation the children are able to focus their attention, control their emotion and manage their thinking, behaviour, and feelings. Moreover, selfregulation emerge early in life and are important to children's school achivement and social competence with peers, adults, and the social environment. The development of effective self-regulation is recognized as fundamental to an individual's functioning, with development during early childhood often considered an early marker for later life successes (Blair, 2003; Bronson, 2000; McClelland \& Cameron, 2012). But every child is different. Although every child will through the same pattern in development but child have their own characteristics. Some easily expressing their ideas but, some have difficulty expressing their ideas verbally. Therefore, child needs some help to regulate thinking, behaviour through words and expressing their emotion, and early childhood teachers play an important role in it.

The activities in the classroom are demanding child to regulate their self. Effective self-regulation in the classroom requires that the child seamlessly coordinate multiple aspect of top-down control, such as attention, 
working memory, and inhibitory control, along with motor or verbal function to produce overt behaviors, such as remembering multistep directions amid distraction (Cameron Ponitz et al., 2008; McClelland et al., 2007). Children who exhibit self-regulatory behaviors, such as paying attention and focusing on a task, are more likely to benefit from mathematical learning opportunities presented in the classroom (Matthew et al., 2009). Young children's self-regulatory behaviors play an important role in their number sense achivement (Ivrendi A, 2011) school readiness, and cognitive skill (Blair, 2003).

Based on research that between ages 3 and 7 years, a qualitative shift in self-regulation may take place when children typically progress from reactive or coregulated behavior to more advanced, cognitive-behavioral forms of self-regulation (Diamond, 2002; Kopp, 1982). Moreover, active play is promoting self-regulation and academic achievement (Becker, McClelland, Loprinzi, \& Trost, 2013). Although there is evidence supporting the notion that self-regulation can be improved through intervention, but there are still little research has discussed and examined this from phisical activity or movement. Therefore, this research will discuss selfregulation from phisical activity perspective. The purpose of this study was to examine the effect of gross motor activity, through task of gross motor, on self regulation of preschool children.

\section{Self-Regulation}

Self-regulation refers to several complicated processes that allow children to appropriately respond to their environment (Bronson, 2000), operating across several levels of function (e.g., motor, physiological, socialemotional, cognitive, behavioral and motivational), which, in its broadest sense, represents the ability to volitionally plan and, as necessary, modulate one's behaviour(s) to adaptive end (Barkley, 2011; Gross \& Thompson, 2007). The component skills that form the construct of self-regulation are crucial for developing the habits and behaviors that carry children through a successful academic career (Becker, McClelland, Loprinzi, and Trost: 2014), established that attention to learning task was more highly correlated with achievement than time on task (Stewart, Rule, and Giordano, 2007). Moreover, developing the children self-regulation, can improve the children abilities to control their temperamental emotional reactivity.

Self-regulation of behaviour generally refers to controlled, cognitive monitoring of the actions and steps required to obtain a goal, or to bring about a desired response from the environment (Blair, 2003). Selfregulation helps young children manage the transition to middle childhood, where they will be expected to act independently as thinkers and play-mates (Cooper, 2007). Therefore, self-regulation have an important role in the children development.

\section{Gross Motor Activity}

Movement is a part of children's live. Through movement the children can improve their gross motor skill, and movement is one of the gross motor activity. The gross motor activity are included the locomotors (i.e., running, galloping, hopping, leaping, jumping, and sliding) (Haywood \& Getchell, 2009), and object control (i.e., throwing, catching, kicking, dribbling, and underhand rolling) (Logan et al, 2012). The gross motor skill is one of the important aspect in the early childhood development (Reed, 2017).gross motor development is characterized by physical skills to perform activities that generally involve the whole body, especially large muscles. Gross motor skills refer to skills such as static and dynamic balance, strength and agility, and general body coordination (Wang, 2009). Important to give an opportunity of gross motor activity for children through the simple task, and presenting each task that is motivating, stimulating, and suitable for the children's level or giving the children chance to explore their environment through natural outdoor. At natural outdoor children have big opportunities to increase their gross motor skill, they are have a chance to walking on the grass, running, jumping through the stone, and play in the play ground. Moreover, through the gross motor activities such as free play children can express their thinking and feeling, social, and emotional. It allows children to develop creative thinking, problem-solving skills, and motor skill abilities (Wang, 2009). The gross motor activity provides many benefits on the children development process. 


\section{Methods}

\subsection{Participant}

Participants included 40 children attending preschool in a kindergarten in Bantul Yogyakarta Indonesia. A total of 13 of the children were male, and 27 were female $(n=40)$. Data from 40 children were used for the test reliability procedure of gross motor skill and Head, Toes, Knees, and Shoulders (HTKS) instruments, and were used for the further analysis.

\subsection{Data Analysis}

In order to determine whether self regulation, and gross motor activity, simple linear regressions using stepwise method were computed on the data.

\section{Result}

The results of data analysis from the total subjects are 40 kindergarten children. The preschool children ages 5-6 years were selected from two preschool, and each preschool is included 5 years and another is 6 years. Onesample Kolmogorov-Smirnov Test with self-regulation and gross motor activity as a variable showed that normal distributions, and The Test of Homogeneity of Variances obtained a result of the significance of 0,877 which means the data is homogeneous. The level of significance was set at 0,05 . Based on the linearity test $\mathrm{F}=$ $2.15>1.387$, while the value of significance obtained value of $0.234>0.05$ and there is a significant linear relationship between $\mathrm{X}$ and $\mathrm{Y}$. The significance value is $0.000<0.05$, its mean the $\mathrm{H} 0$ is rejected and $\mathrm{Ha}$ is accepted $(\mathrm{a} / 2=0.05 / 2=0.025)$, and when examined the effect of predictive variables and dependent variable through $\mathrm{T}$ value $=4.065>2.021$, there was an effect of the gross motor activity on self-regulation of preschool children. Based on $\mathrm{R}$ square $=0.303$ that the effect of gross motor activity on self-regulation of preschool children is $30.3 \%$ while $69.7 \%$ the children self-regulation are affected by other variables that are not examined.

TABLE I: Results of Simple Linear Regression

\begin{tabular}{|l|l|l|l|l|l|}
\hline Variable & $\mathrm{B}$ & Standard Eror & $\mathrm{B}$ & $\mathrm{t}$ & $p$ \\
\hline Constant & 25.727 & 4.934 & & 5.215 & .000 \\
\hline $\mathrm{HTKS}$ & .542 & .133 & .551 & 4.065 & .000 \\
\hline $\mathrm{R}=.303$ & & & & & \\
$\mathrm{~F}=(2.15)=1.387$ & & & & & \\
\hline & $* p<.05$
\end{tabular}

\section{Discussion}

This study investigated the contribution of self-regulated behavior assessed by HTKS and looked at how the effects of gross motor activity on self-regulation of children. Data collecting process was done in two different ways. There are two different classef of preschools in the data collection process. In the first preschool class with an average age of children is 6 years while another preschool class is age 5 years. Taking data of HTKS test for a 6-year-old is to test simultaneously with the number of children in a class are 20 children. While in another class at the age of 5 years, data collectionof HTKS is done through small groups of 20 children divided into 4 groups with each group of 5 children. First children are given a gross motor activity test which includes locomotor (run, gallop, hop, leap, horizontal jump, and slide) and object control (dribble, kick, catch, overhand throw, and underhand roll), when the data of gross motor was collected then carried out the HTKS test.

The gross motor test did in a fun way, and give the children a challenging experiences so the child does not feel like they are being tested. In the process of object control the tests such as dribble, kicking a ball, catching a small ball, overhand throw, and underhand roll is done by alternately one by one. As for locomotor test such as running, galloping, hoping, leaping, jumping, and sliding is done through a race performed with every two children in turn. In the test, the children through several processes to give more attention, respond to commands, and also make various calculation in each test performed. The children must learn to evaluate anything what they see, hear, touch, and compare it to what they already know (Florez, 2011). In this process, delf-regulation is 
using to communicate with any number of system (such as language system or motor system) to choose any carry out a response. In this situation, the children must be translated any instruction from adult, such as "Stay in your line, its not your turn" into regulation that helps them inhibit urges to grab a queue. The gross motor activity can help children to get many experiences, interactions, and through gross motor activity the children can develop they attention, emotion and motivation, then can develop their regulation skills. Because children need many opportunities to practice with adults and capable peers through experience and interaction.

Based on data both gross motor activity and HTKS were processed using simple linear regression. It was found that there was a significant influence of both variables. During the process of collecting data on gross motor activities, the child must perform activities in accordance with the instructions of the teacher, so in the process the child must focus and remember the command and make some estimates for the order can be done properly. In the task every children have a same chance and the task was did with playing. Thus, in the process of this gross motor activity, the child activates cognitive, motor function, coordination between the two aspects as well as making calculations in the execution of the activity, or such play planning servers as the precursor to reflective thinking, another aspect of self-regulatory behavior. For example, when a child is asked to capture and throw a small ball, the child must be able to estimate at what time the ball can be caught, and at what distance the ball should be thrown back, so that it can be caught. Based on the data obtained, the value of child HTKS at age 5 years in small group is higher than children in large group. Based on the findings it is known that the quantity in the class can affect the process of self-regulation of the child both in attention, behavior and memory recall.

The findings relate to the number of children in the classroom as well as the favorable conducive situation associated with the child's self-regulation behavior, and there are differences in the child's self-regulation behavior, especially in terms of receiving attention. Children in small classes have higher attention than in large numbers, because the situation is more conducive than large classes. Another finding of this study is that gender is also linked to the child's self-regulation behavior. Based on the mean values of child HTKS it was found that girls had higher HTKS scores than boys. This finding is consistent with previous research that self-regulation demonstrated that children's self-regulation of behavior was associated with and most significant predictor of mothers' educational level, gender, and age (Ivrendi, 2011; Montroy, Bowles, Skibbe, McClelland, and Morrison, 2016).But from the overall results found that gross motor activity affects the self-regulation behavior of both male and female children.

Each grade either 6 or 5 years has a routine priority before they enter the classroom. Such activities in the form of gross motor activities conducted outdoor and free play. Because for children, play becomes the first activity in which children are driven not by the need for instant gratification-prevalent at this age -but instead by the need to suppress their immediate impulses (Bodrova, Germeroth, and Leong, 2013). Furthermore, the gross motor activity has prepared by the teacher through structured and planned activities, and each activity is accompanied by the rules, and instruction. During the process of the child's activities get a lot of experience, they interact with friends and make some deals to be able to use the toys alternately or simultaneously, or such play planning servers as the precursor to reflective thinking, another aspect of self-regulatory behavior. The findings revealed that the children exposed to mindful movement, where they learned and played in a learning environment in which they could experience mindful movements, attained a significantly higher level of achievement than the children engaged in other physical activity framework (Shoval, Sharir, Amon, and Tenenbaum, 2017). The children do a lot of interaction through the activities of gross motor activity, children gain more social knowledge, so as to make children more adaptable.

\section{Acknowledgements}

The research and preparation of this manuscript is supported by the following grant: Lembaga Pengelola Dana Pendidikan (LPDP) Indonesia. 


\section{References}

[1] JJ. Montory, RP. Bowles, and LE. Skibbe, MM. McClelland, FJ. Morrison, "The Development of Self-Regulation Across Early Childhod” Developmental Psychology. On American Psychological Association, vol. 52, pp. 1744-1762, 2016.

[2] Bronson. M.B, Self-Regulation in Early Childhood: Nature and Nurture, New York. NY: Guilford Press, 2000.

[3] McClelland.M.M, Cameron Ponitz. C.E., "Self-Regulation in Early Childhood: Improving Conceptual Clarity and Developing Ecologically Valid Measures,”. Child Development Perspectives, vol. 6, pp. 136-142, 2012. https://doi.org/10.1111/j.1750-8606.2011.00191.x

[4] Cameron Ponitz. C.E., McClelland. M.M., Jewkes. A.M., Connor. C.M., Farris. C. L, \& Morrison. F.J, “Touch Your Toes! Developing a Direct Measure of Behavioral Regulation in Early Childhood," Early Childhood Research Quarterly, vol. 23, pp. 141-158, 2008.

https://doi.org/10.1016/j.ecresq.2007.01.004

[5] Becker. D.R, McClelland. M.M, Loprinzi. P, \& Trost S.G, "Physical Activity, Self-Regulation, and Early Academic Achievement in Preschool Children," Early Education and Development, vol. 25:1, pp. 56-70, 2013. https://doi.org/10.1080/10409289.2013.780505

[6] Shoval. E, Sharir. T, Arnon. M, \& Tenenbaum. G,'The Effect of Integrating Movement into the Learning Environment of Kindergarten Children on their Academic Achievements," Early Childhod Education Journal: Springer, 2017.

[7] Ivrendi. Asiye, "Influence of Self-Regulation on the Development of Children's Number Sense," Early Childhood Education Journal, vol. 39, pp. 239-247, 2011. https://doi.org/10.1007/s10643-011-0462-0

[8] Wang. J. Hui-Tzu. "A Study on Gross Motor Skills of Preschool Children". Journal of Research in Childhood Education, vol. 19(1), pp. 32-43, 2009.

[9] Bodrova. E, Germeroth. C, \& Leong. D.J, "Play and Self-Regulation Lesson from Vygotsky," American Journal of Play, vol. 6, pp.111-123, 2013.

[10] Blair. Clancy, "Self-Regulation and School Readiness," Eric Digest, pp. 1-9, 2003. Available: www.eric.ed.gov.

[11] Cooper. P.M, "Teaching Young Children Self-Regulation Through Children's Books," Early Childhood Education Journal, vol. 34, pp. 315-322, 2006. https://doi.org/10.1007/s10643-006-0076-0

[12] Reed. S, "Gross Motor in the Preschool Classroom," M.S. thesis, Dept. Health and Physical Education. Eng., Northwestern College-Orange City, 2017.

[13] Haywood. K.M, \& Getchell. N, Lifespan Motor Development, $5^{\text {th }}$ edition, Champaign, IL:Human Kinetics, 2009.

[14] Stewart. R.A, Rule. A.C, Debra A, \& Giordano, "The Effect of Fine Motor Skill Activities on Kindergarten Student Attention,” Early Childhood Education Journal, vol. 35, pp. 103-109, 2007.

https://doi.org/10.1007/s10643-007-0169-4

[15] Logan. S.W, Robinson. L.E, Webster. E.K, Lucas. W.A, \& Barber. L.T,'”Teaching Practices that Promote Motor Skills in Early Childhood Settings," Early Childhood Education Journal, vol. 40, pp. 79-86, 2012. https://doi.org/10.1007/s10643-011-0496-3

[16] Matthews. J. S, Ponitz. C.C, \& Morrison. F. J, "EarlyGender Differences in Self-Regulation and Academic Achievement," Journal of Educational Psychology, vol 101, pp. 689-704, 2009. https://doi.org/10.1037/a0014240

[17] Florez. IR, “Developing Young Children's Self-Regulation through Everyday Experiences,” NAEYC, pp. 46-51, 2011. Available: www.naeyc.org/yc

[18] Kopp. C.B, Antecedents of Self-Regulation: A Developmental Perspective.“ Developmental Psychology, vol. 18, pp. 199-214, 1982. https://doi.org/10.1037/0012-1649.18.2.199 